
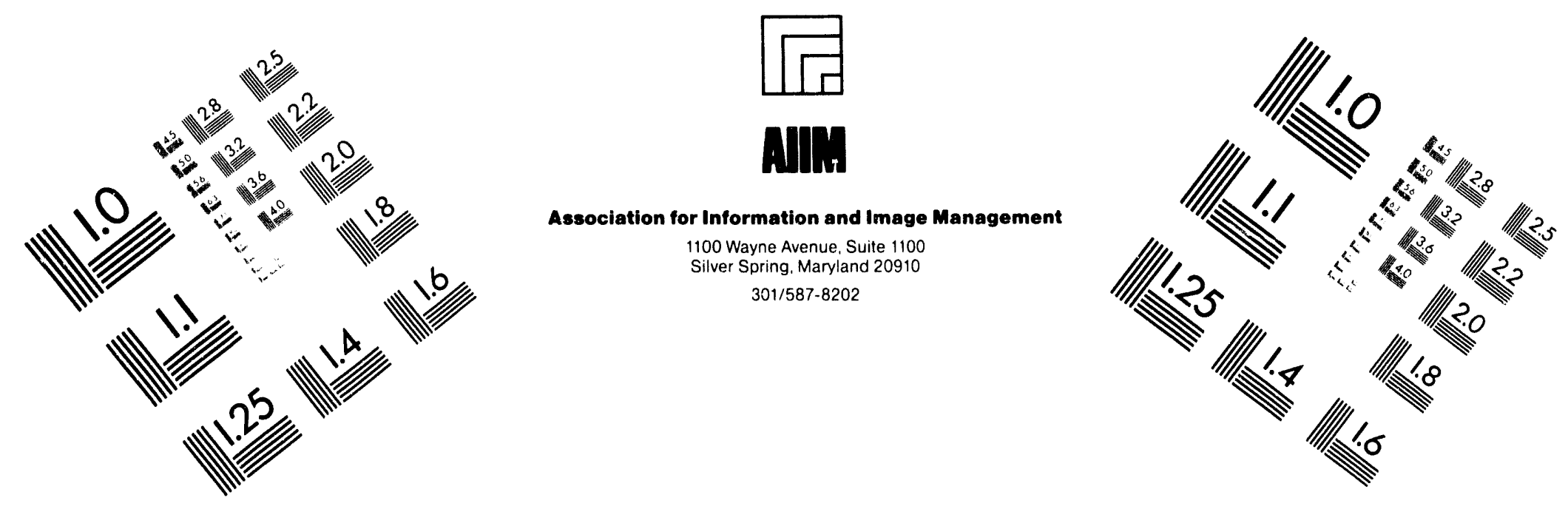

\title{
Centimeter
}

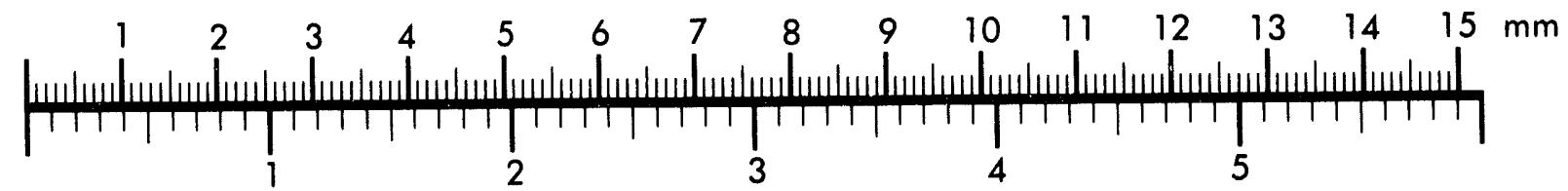
Inches
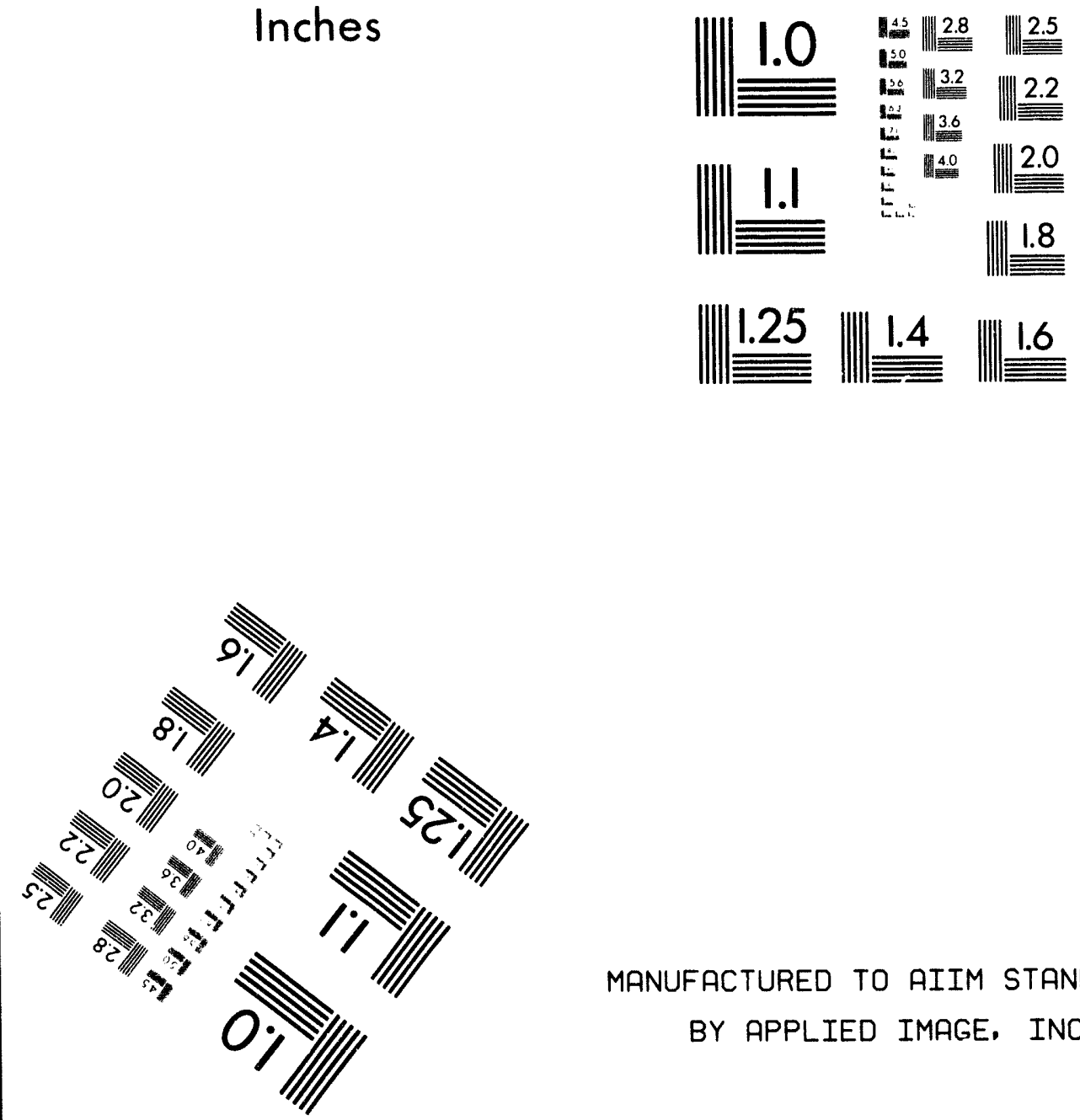

MANUFACTURED TO AIIM STANDARDS BY APPLIED IMAGE, INC.

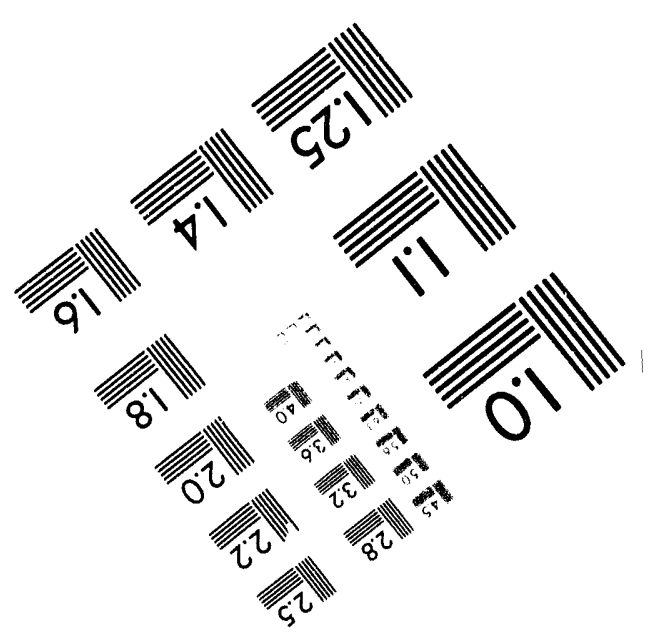



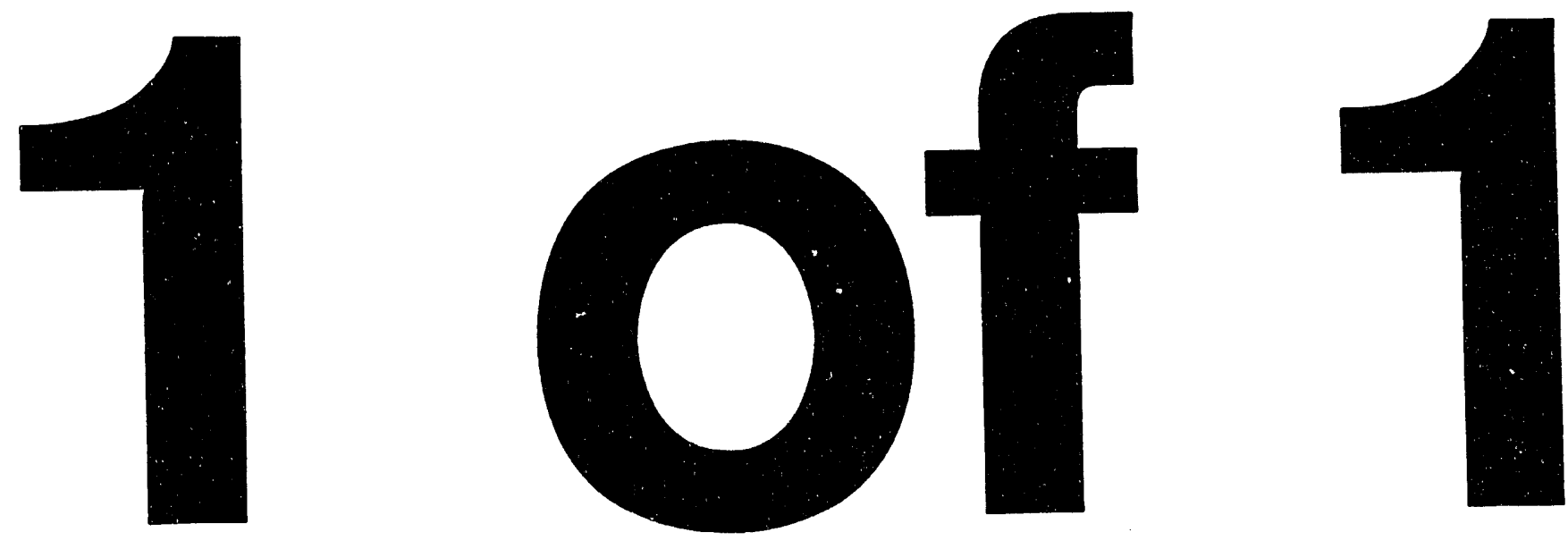


\section{HETEROGENEOUS NUCLEATION OF CALCIUM OXALATE ON NATIVE OXIDE SURFACES}
L. Song
B. C. Bunker
M. J. Pattillo
G. L. Graff
A. A. Campbell

April 1994

Presented at the

Monitored Retrievable Storage Spring

Meeting '94

April 4-8, 1994

San Francisco, California

Prepared for

the U.S. Department of Energy

under Contract DE-AC06-76RLO 1830

Pacific Northwest Laboratory

Richland, Washington 99352

\section{DISCLAIMER}

This report was prepared as an account of work sponsored by an agency of the United States Government. Neither the United States Government nor any agency thereof, nor any of their employees, makes any warranty, express or implied, or assumes any legal liability or responsibility for the accuracy, completeness, or usefulness of any information, apparatus, product, or process disclosed, or represents that its use would not infringe privately owned rights. Reference herein to any specific commercial product, process, or service by trade name, trademark, manufacturer, or otherwise does not necessarily constitute or imply its endorsement, recommendation, or favoring by the United States Government or any agency thereof. The views and opinions of authors expressed herein do not necessarily state or reflect those of the United States Government or any agency thereof. 


\title{
HETEROGENEOUS NUCLEATION OF CALCIUM OXALATE ON NATIVE OXIDE SURFACES
}

LIN SONG, MICHAEL J. PATTRLO, GORDON L. GRAFF, ALLISON A. CAMPBELL, AND BRUCE C. BUNKER

Pacific Northwest Laboratory(a), Materials Sciences Department, Richland, WA 99352

\begin{abstract}
The aqueous deposition of calcium oxalate onto colloidal oxides has been studied as a model system for understanding heterogeneous nucleation processes of importance in biomimetic synthesis of ceramic thin films. Calcium oxalate nucleation has been monitored by measuring induction times for nucleation using Constant Composition techniques and by measuring nucleation densities on extended oxide surfaces using an atomic force microscope. Results show that the dependence of calcium oxalate nucleation on solution supersaturation fits the functional form predicted by classical nucleation theories. Anionic surfaces appear to promote nucleation better than cationic surfaces, lowering the effective energy barrier to heterogeneous nucleation.
\end{abstract}

\section{INTRODUCTION}

Biomimetic synthesis of ceramic thin films involves crystal nucleation from supersaturated aqueous solutions onto substrate surfaces. Nucleation is stimulated using surface functional groups that mimic the role of active biomineralization proteins. The process can be used for low temperature deposition of oxides, hydroxides, sulfides, phosphates, and carbonates for applications ranging from producing hard coatings on plastics to producing biocompatible coatings for porous bone implants [1].

Classical theories [2] predict that the free energy for nucleation in biomimetic processing should depend on the level of solution supersaturation (S), the net interfacial energy for nucleation $(\sigma)$, the temperature $(T)$, and the particle surface area $(A)$ :

$$
\Delta \mathrm{G}=-\mathrm{RT} \ln S+\sigma \mathrm{A}
$$

Critical parameters for film formation including the nucleation induction time $(\tau)$, nucleation density $(\mathrm{N})$, and particle growth rate (dr/dt) are also controlled by $S, \sigma$, and $T$ :

$$
\begin{aligned}
& \left.\ln (1 / \tau)=\ln \mathrm{B}-16 \pi \sigma^{3} \vee^{2} /\left[3(\mathrm{kT})^{3}(\ln \mathrm{S})^{2}\right)\right] \\
& \ln \mathrm{N}=\ln \mathrm{P}-\mathrm{Q} \beta \sigma^{3} \vee^{2} /\left[(\mathrm{kT})^{3}(\ln \mathrm{S})^{2}\right] \\
& \mathrm{dr} / \mathrm{dt}=\mathrm{K}(\mathrm{S}-1)^{\mathrm{n}}
\end{aligned}
$$

where $K, \beta, P, Q, B$, and $n$ are constants, $k$ is Boltsmann's constant, and $v$ is the molecular volume of the precipitating phase.

The key to successful biomimetic proceseing is to modify the substrate surface so that the net interfacial energy for nucleation on the surface is lower than the interfacial energy

(a) Operated for the U. S. Department of Energy by Battelle Memorial Institute under Contract DE-AC06-76RLO 1830. 
associated with homogeneous nucleation and precipitation within the bulk solution. The purpose of this investigation is to use nucleation experiments to measure effective interfacial energies for both homogeneous and heterogeneous nucleation to try to determine factors that control interfacial energies. Once the factors that contribute to lowering the nucleation barrier are understood, it will be easier to modify substrate surfaces to promote film formation.

Calcium oxalate $(\mathrm{CaOx})$ was selected as a model nucleating system because its solubility is well known [3] and is constant between $\mathrm{pH} 4$ and $\mathrm{pH} \mathrm{11.} \mathrm{Supersaturation} \mathrm{levels}$ are relatively easy to control for $\mathrm{CaOx}$ over a wide range of solution conditions. The main substrates investigated include colloidal particles of the simple oxides silica, titania, and alumina. The above oxides each exhibit unique surface charge characteristics in the $\mathrm{pH}$ window of interest (Fig. 1) [4]. The surface charge can control the degree to which $\mathrm{Ca}^{2+}$ and $\mathrm{O} \times 2$ - ions are adsorbed or complexed in addition to controlling the contribution that the electrical double layer makes to the net interfacial energy. Each oxide also exhibits different lattice spacings and elastic constants. The interfacial strain energy for $\mathrm{CaOx}$ growing on each oxide is expected to be different, allowing investigation of the role of lattice mismatch in mediating surface nucleation.

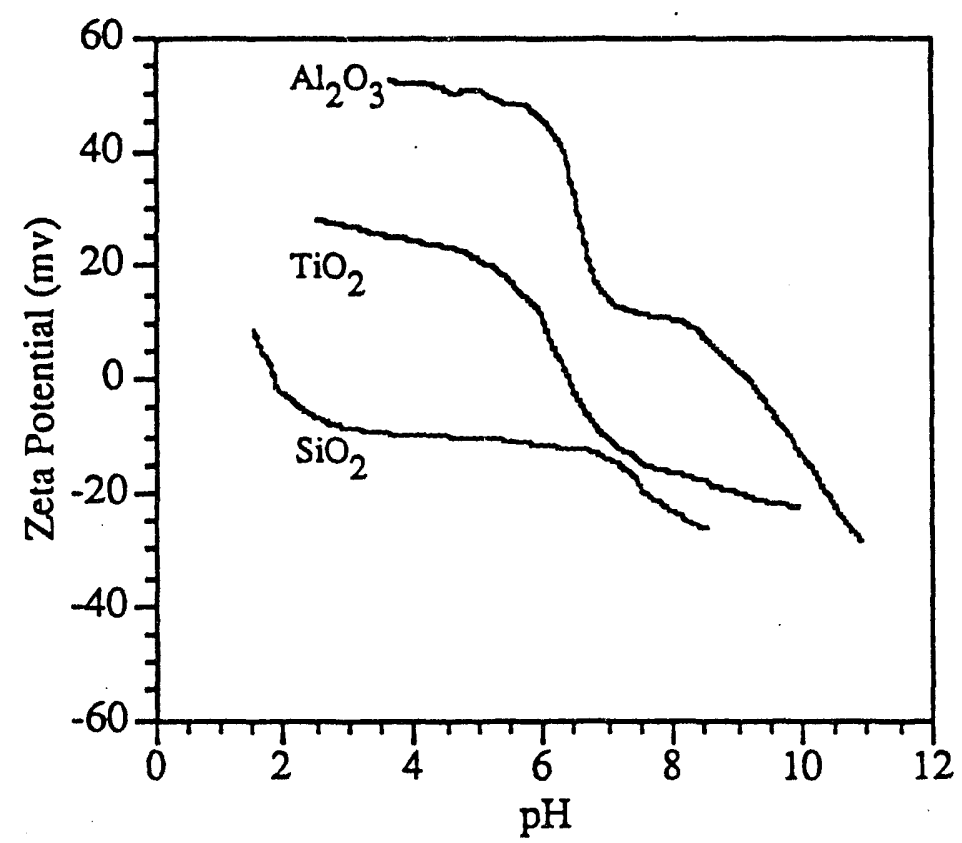

Figure 1. Zeta potentials of $\mathrm{Al}_{2} \mathrm{O}_{3}, \mathrm{TiO}_{2}$ and $\mathrm{SiO}_{2}(0.5 \mathrm{v} / \mathrm{v} \%)$ as a function of $\mathrm{pH} . \mathrm{T}=25 \circ \mathrm{C}$, in $0.01 \mathrm{M} \mathrm{NaCl}$.

\section{EXPERMMENTAL}

The commercial powders $\alpha-\mathrm{Al}_{2} \mathrm{O}_{3}$ (AKP-30, Sumitomo, surface area $=6.8 \mathrm{~m} 2 / \mathrm{gm}$ ), $\mathrm{SiO}_{2}$ (PST-3, Nissan, $\left.15 \mathrm{~m}^{2} / \mathrm{gm}\right), \mathrm{TiO}_{2}$ (P25, Degussa, $57 \mathrm{~m} 2 / \mathrm{gm}$ ) and $\mathrm{BaSO}_{4}$ (Baker,6.8 $\mathrm{m}^{2} / \mathrm{gm}$ ) were used in Constant Composition (CC) experiments. Colloids were dispersed ultrasonically in $0.01 \mathrm{M} \mathrm{NaCl}$ solutions adjusted to the desired $\mathrm{pH}$ using $\mathrm{HCl}$ or $\mathrm{NaOH}$ and equilibrated for at least three days prior to $\mathrm{CC}$ experiments.

Stock solutions of calcium chloride and potassium oxalate were prepared from reagent grade chemicals (Fisher) using deionized, $\mathrm{CO}_{2}$-free water and were passed through $0.2 \mu \mathrm{m}$ Millipore filters before use. CC experiments were initiated by adding the desired colloidal slurry to freshly prepared supersaturated solutions containing equal $\mathrm{Ca}^{2}+$ and $\mathrm{Ox}^{2}$ - 
concentrations. As $\mathrm{Ca}^{2}+$ was consumed by formation of $\mathrm{CaOx}$, a calcium ion electrode commanded burettes to add $\mathrm{Ca}^{2}+$ and $\mathrm{Ox}{ }^{2}$ - to the solution to keep solution supersaturation constant. Calcium consumption during $\mathrm{CaOx}$ formation was recorded with time to monitor nucleation induction times and crystal growth rates.

Nucleation densities were measured on single crystals of $\mathrm{TiO}_{2}((110)$ and $(100)$ orientations, Princeton Scientific) exposed to supersaturated $\mathrm{CaOx}$ solutions. After immersion for fixed exposure times, samples were removed, rinsed with deionized water, and examined using a Nanoscope III atomic force microscope (Digital Instruments). The number density of $\mathrm{CaO}$ crystals was determined by manual counting in several different fields of view.

\section{RESULTS AND DISCUSSION}

Bounding values for nucleation induction times are zero (for the case where $\mathrm{CaOx}$ seeds are used) and the time required for "spontaneous" nucleation that occurs on submicron particles of unknown origin that are always present in solution." Addition of colloids to solution can lead to induction times that are shorter than the spontaneous inductions times only when the added particles are more effective nucleation centers than the foreign particles that are already present. Depending on supersaturation levels, CC results (Fig. 2) show that addition of oxides can lower induction times for nucleation (obtained by extrapolating steady state slopes for $\mathrm{Ca}^{2+}$ consumption back to zero). For effective colloids such as silica, the difference between heterogeneous and homogeneous (spontaneous) induction times increases as $S$ decreases. In all cases, the dependence of induction times with $S$ fits the predictions of classical nucleation theory. A plot of $\log (1 / \tau)$ vs. $(\log S)^{-2}$ yields a straight line (see Eq. 2) whose slope can be used to calculate $\sigma$ (Fig. 3).

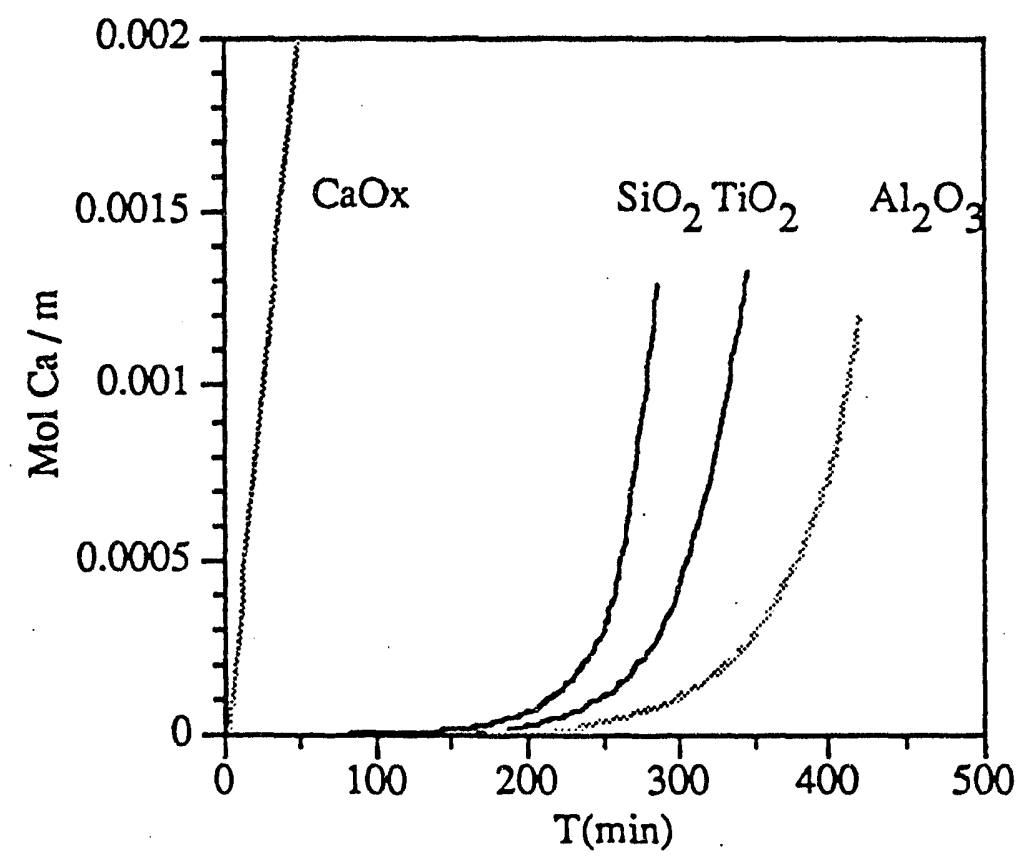

Figure 2. CaOx crystallization on different colloidal surfaces as a function of time at $25 \circ \mathrm{C}$. $\left[\mathrm{Ca}^{2}+\right]=\left[\mathrm{Ox}^{2}-\right]=2.00 \times 10^{-4} \mathrm{M}(\mathrm{S}=3.3)$

The $\sigma$ values calculated from CC data are summarized in Table I, including literature data for $\mathrm{CaOx}$ formation on apatite [3]. The interfacia.. energy for truly homogeneous 


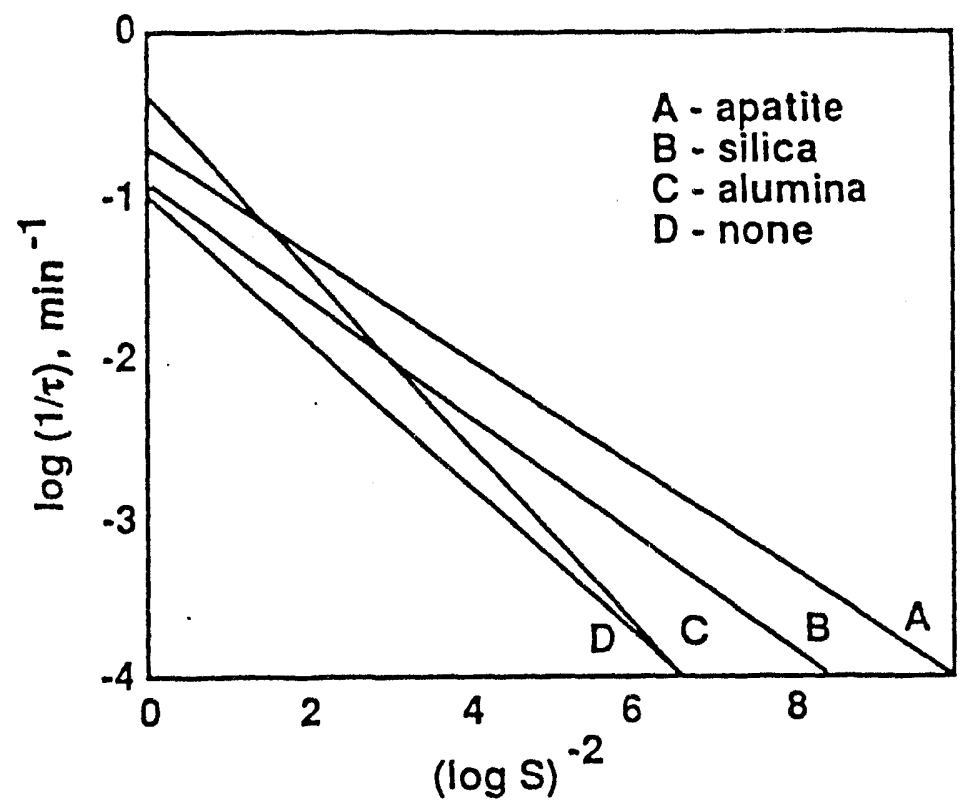

Figure 3. $\log (1 / \tau)$ versus $(\operatorname{logS})^{-2}$ for $\mathrm{CaO}$ nucleation on aparite [3], $\mathrm{SiO}_{2}, \mathrm{Al}_{2} \mathrm{O}_{3}$, and spontaneous nucleation.

Table I. Interfacial Energies $(\sigma)$ of Various Surfaces Measured at $25^{\circ} \mathrm{C}$. Ionic Strength $=$ $0.01 \mathrm{M} \mathrm{NaCl}$.

\begin{tabular}{ll}
\hline Surface & $\sigma\left(\mathrm{mJ} / \mathrm{m}^{2}\right)$ \\
\hline homogeneous & $69[1]$ \\
spontaneous (unseeded) & 31 \\
apatite & $21[2]$ \\
$\mathrm{BaSO}_{4}$ & 41 \\
& 37 \\
$\mathrm{Al}_{2} \mathrm{O}_{3}(+)$ & 25 \\
$\mathrm{TiO}_{2}(0)$ & 24 \\
$\mathrm{SiO}_{2}(-)$ & 37 \\
$\mathrm{TiO}_{2}(+)$ & 25 \\
$\mathrm{TiO}_{2}(0)$ & 25 \\
$\mathrm{TiO}_{2}(-)$ & \\
\hline
\end{tabular}

1. Reported in ref. [5].

2. Calculated from data in ref. [3].

nucleation is reported to be $69 \mathrm{~mJ} / \mathrm{m}^{2}$ [5]. The value of $31 \mathrm{~mJ} / \mathrm{m}^{2}$ obtained here for spontaneous nucleation agrees with the literature value [5]. Results for the intentionally added colloids fall into two groups: colloids that are less effective than the particles responsible for spontaneous nucleation $\left(\sigma=37-41 \mathrm{~mJ} / \mathrm{m}^{2}\right)$, and colloids that appear to stimulate $\mathrm{CaOx}$ nucleation $\left(\sigma=21-25 \mathrm{~mJ} / \mathrm{m}^{2}\right)$. For the case of $\mathrm{TiO}_{2}$, the value of $\sigma$ determined from AFM investigations of both (110) and (100) faces is in exact agreement with the value of $\sigma$ calculated 
from CC results $\left(24 \mathrm{~mJ} / \mathrm{m}^{2}\right)$.

The experimental values for interfacial energies can be used to examine trends and to establish whether observed changes in $\sigma$ on different substrates are consistent with existing theories regarding interfacial energies. First, it appears that positively charge surfaces $\mathrm{CTiO}_{2}$ at $\mathrm{pH} 5$ and $\mathrm{Al}_{2} \mathrm{O}_{3}$ at $\mathrm{pH} 6.5, \sigma=37 \mathrm{~mJ} / \mathrm{m}^{2}$ ) are not effective at nucleating $\mathrm{CaOx}$, while neutral and negative oxide surfaces $\left(\mathrm{TiO}_{2}\right.$ at $\mathrm{pH} 6.5$ and $\mathrm{pH} 8$ and $\mathrm{SiO}_{2}$ at $\mathrm{pH}$ 6.5) promote $\mathrm{CaOx}$ formation to an identical extent $\left(\sigma=24-25 \mathrm{~mJ} / \mathrm{m}^{2}\right.$ for all three). As a further :heck of this observation, $\mathrm{CaOx}$ nucleation has been determined for $\mathrm{Al}_{2} \mathrm{O}_{3}$ at $\mathrm{pH} 6.5$ having an adsorbed layer of the anionic surfactant dextran sulfate (Sigma). To date, the measured induction times are identical to those measured for silica at $\mathrm{pH} 6.5$, indicating that the charge is indeed influencing nucleation times. The surface charge effect does not correspond to the change in interfacial energy predicted for the electrical double layer, because similar changes in interfacial energy result for both positive and negative surface charges. Instead, it appears that surfaces capable of adsorbing or complexing $\mathrm{Ca}^{2+}$ (including apatite) are more effective than surfaces having a higher affinity for $\mathrm{Ox}^{2}$ - when it comes to nucleating $\mathrm{CaOx}$. Further experiments are planned to test this hypothesis.

The measured interfacial energies indicate that interfacial strain is not a major contributor controlling the nucleation process. The results are not consistent with a process that is controlled by epitaxial relationships between the nucleating crystal and the substrate. For the extended crystal-substrate interface, it is possible to estimate the interfacial strain energy based on the degree of lattice mismatch and the elastic constants of the crystal and the substrate [6]. Estimates for the strain energy range from around $40 \mathrm{~mJ} / \mathrm{m}^{2}$ for the $\mathrm{CaOx}: \mathrm{SiO}_{2}$ interface to around $120 \mathrm{~mJ} / \mathrm{m}^{2}$ for the $\mathrm{CaOx}: \mathrm{TiO}_{2}$ interface. Since the interfacial strain energies are large relative to the total interfacial energy for sponianeous nucleation, none of the colloidal oxides should be capable of nucleating $\mathrm{CaOx}$ if epitaxy is critical. The fact that different oxides having similar surface charges result in identical effective interfacial energies for $\mathrm{CaOx}$ nucleation reinforces this conclusion, as does the observation that nucleation on single crystal $\mathrm{TiO}_{2}$ is insensitive to the orientation of the nucleating surface $((110)$ vs. (100)). Perhaps the insensitivity of the observed nucleation barrier to interface is due to the fact that the size of the critical nucleus is so small (a few ions for the range of $S$ studied here) that adsorption by, rather than alignment with the lattice is most critical. The nucleus is so small that it can adapt to local bonding configurations rather than being forced to lattice match over an extended distance.

\section{CONCLUSIONS}

Nucleation of calcium oxalate from supersaturated aqueous solutions onto colloidal oxide particles is fit by classical nucleation theories. The dependence of both nucleation induction times and nucleation densities (on extended surfaces) fit theoretical predictions and can be used to extract experimental values for parameters such as the interfacial energy associated with nucleation. For $\mathrm{CaOx}$, anionic and neutral colloidal surfaces appear to be more effective than cationic surfaces in promoting nucleation. Cationic surfaces can be activated to nucleate $\mathrm{CaOx}$ via adsorption of anionic surfactants. Contributions to the net interfacial energy to nucleation due io electrical double layers and interfacial strain appear to be less important than the ability of the surface to complex $\mathrm{Ca}^{2+}$.

\section{ACKNOWLEDGEMENTS}

This work was supported by the Office of Basic Energy Sciences, Department of Energy, under Grant ED-38-03-00-0, and by Associared Western Universities, Inc. Northwest Division under Grant DE-FG06-89ER-75522 with the U. S. Department of Energy. / 


\section{REFERENCES}

1. B. C. Bunker, P. C. Rieke, B. J. Tarasevich, A. A. Campbell, G. E. Fryxell, G. L. Graff, L. Song, J. Liu and J. W. Virden, Science, in press.

2. R. Mohanty, S. Bhandarkar, and J. Estrin, AIChE Journal, 36(10), 1536 (1990).

3. A. Ebrahimpour, L. Perez, and G. H. Nancollas, Langmuir, 7, 577 (1991).

4. L. Song, A. A. Campbell, and B. C. Bunker, in 1993 MRS Spring Meeting Proceeding. Symposium V, in press.

5. C. M. Brown, D. K. Ackermann, D. L. Purich, and B. Finlayson, J. Crystal. Growth, 108,455 (1991).

6. J. H. van der Merwe, in Treatise on Materials Science and Technology, edited by $\mathrm{H}$. Herman (Academic Press, New York, 1973), p. 1. 



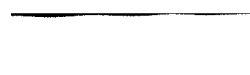

